\title{
ETNOMATEMÁTICA COMO INTERMEDIADORA ENTRE OS CONHECIMENTOS MATEMÁTICO ESCOLAR E MATEMÁTICO POPULAR
}

\author{
Ethnomath as a mediator between Math Knowledge acquired in School and \\ Popular Knowledge about Math
}

\author{
Francisco Hermes Santos da Silva' ${ }^{1}$ Evanilde Corrêa Souza ${ }^{2}$
}

\section{RESUMO}

Neste trabalho, o objetivo foi relatar uma experiência de sala de aula e, a partir deste relato, compreender as relações possíveis entre conhecimento matemático escolar e conhecimento matemático popular à luz de alguns conceitos teóricos. Conclui-se ao final, que para desenvolver experiências dessa natureza, o professor deve abrir espaços em suas aulas para que os alunos possam emitir e discutir suas opiniões e interpretações, explorando seus conhecimentos prévios e fazê-los registrar e discutir coletivamente suas idéias em classe.

Palavra-chave: Etnomatemática, conhecimento matemático escolar e conhecimento matemático popular.

\section{ABSTRACT}

This is a report on a classroom experience in the attempt to understand the relation between Math Knowledge acquired in School and Popular Knowledge about Math. Analysis is carried out by means of using traditional theoretical concepts. The result of such experience indicates that teachers must promote discussion among students to explore their previous knowledge and ideas as they arrive in the classroom.

Key Words: Ethnomath, Math Knowledge acquired in School, Popular Knowledge about Math.

\section{INTRODUÇÃO}

As leituras e discussões efetuadas, quando do desenvolvimento da disciplina Fundamentos de Aritmética do curso de Especialização em Educação Matemática do Núcleo Pedagógico de Apoio ao Desenvolvimento Científico da Universidade Federal do Pará, e uma pesquisa bibliográfica posterior forneceram subsídios para a definição de pressupostos orientadores deste artigo.

Tomou-se como eixo central para análise: "Etnomatemática como elo entre os conhecimentos matemático escolar e popular: experiência na escola $\mathrm{S}$. Pedro na comunidade Mocajatuba-PA".
O interesse em refletir, partindo do eixo proposto, relaciona-se a nossa experiência como professora e ministrando da disciplina Matemática. Considera-se a mesma como um marco de reflexões sobre a Matemática escolar e a Matemática do cotidiano, observando-se as discussões dos alunos e as suas preocupações em estudar e aprender.

O artigo trabalha questões relevantes como: reflexões sobre o ensino da Matemática; apresentação dos aspectos gerais da comunidade de Mocajatuba; considerações gerais sobre a evolução do pensamento matemátice, com base em textos de diversos autores que refletem sobre 0 ensino da Matemática, bem como da Educação Matemática; e relatu sobre uma experiência vivida na comunidade Mocajatuba-PA na disciplina Matemática.

Ressalte-se a importância deste trabalho, visando ampliar o conhecimento sobre a Matemática na prática pedagógica e social.

\section{COMUNIDADEMOCAJATUBA-PA: ASPECTOS GERAIS}

A comunidade Mocajatuba-PA situa-se no município de Cametá-PA. A população da comunidade é urbano-rural e de aproximadamente 600 pessoas, distribuídas entre 120 famílias de pequenos agricultores, cuja renda provém basicamente do trabalho de campo. As propriedades estão distribuidas numa média de quatro hectares por família, cuja atividade é a agricultura de subsistência (milho, mandioca, e batata-doce) e pequeno cultivo de frutas (banana, açai e abacaxi). Algumas famílias criam animais de pequeno porte.

A comunidade fica a 30 quilômetros de Cametá. O transporte entre a comunidade e a sede do município é feita por estradas vicinais pouco cuidadas e que ficam alagadas na época das chuvas.

A área urbana é composta de um posto de saúde, uma escola de ensino fundamental, uma igreja, pequeno comércio e 30 moradias. As más condições de vida da população são agravadas pelas precárias condições sanitárias: a água não é tratada; não existe esgoto; algumas casas não têm fossa. As doenças comuns são: verminose, diarréia e anemias. Quando a safra não é boa, algumas pessoas até passam fome.

\footnotetext{
'Prof. Dr. em Educação Matemática -Núcleo Pedagógico de Apoio ao Desenvolvimento Cientifico / Universidade Federal do Pará

2 Prof. Especialista em Educação Matemática - NPADC/UFPA
} 


\section{OENSINODAMATEMÁTICA: EXPERIÊNCLADA COMUNIDADE MOCAJATUBA-PA.}

\section{Evolução do pensamento matemático: algumas considerações}

Antes de tudo, julga-se necessário tecer comentários sobre a evolução do pensamento matemático.

Nos primórdios da humanidade, as pessoas viviam em grupos, dentro de cavernas. Alimentavam-se de raizes e frutos de plantas silvestres e carne de animais que caçavam.

Já nessa época, os primeiros passos rumo à evolução cognitiva do homem foram dados, partindo da observação da natureza.

Observavam as árvores que lhe davam frutos, sombra, a água que lhes matava a sede; observavam os pássaros, os animais, enfim, tudo que fazia parte do seu meio ambiente.

Deste contexto surgiu a necessidade de contar as quantidades que os rodeavam. Os períodos e ciclos que se sucediam na natureza levou o homem a adquirir as primeiras noções matemáticas. Primeiramente, ele percebeu que existiam quantidades grandes e pequenas.

À medida que o homem passou a viver em grupo e as civilizações foram se formando, ele passou a ter outras necessidades: registrar o tempo, marcar épocas de cheias e de colheitas, organizar um calendário, entre outras. Enfim, o desenvolvimento da humanidade gerou a necessidade de fazer cálculos.

A Matemática, definida hoje como ciência abstrata do espaço, dos números e da quantidade, era praticada pelos antigos egípcios, sumerianos, indianos e chineses de forma rudimentar, especialmente em mapas e para fins comerciais. A Matemática pura, no sentido formal do termo, foi desenvolvida inicialmente pelos gregos e, posteriormente, recebeu contribuições importantes dos árabes, que introduziram os antigos numerais hindus na Europa durante o século X.

A Renascença deu-lhe grande impulso e, no século XVII, houve avanços em muitos campos, com a invenção dos logaritmos, da geometria algébrica e do cálculo. A nova Matemática surgiu no século XX, depois de investigações sobre os fundamentos lógicos da Matemática. A teoria dos conjuntos foi introduzida e a chegada dos computadores impôs sua própria disciplina, libertando também os matemáticos do trabalho enfadonho dos longos cálculos.

\section{Educação Matemática: a socialização do conhecimento matemático acumulado}

Paralelamente ao desenvolvimento do pensamento matemático, por razões sócio-culturais e hegemônicas, o pensamento matemático se impôs de tal forma que, como afirma D'AMBRÓSIO (1993: 10):

A matemática é, desde os gregos, uma disciplina de foco nos sistemas educacionais, e tem sido a forma de pensamento mais estável da tradição mediterrâ- nea que perdura até nossos dias como manifestação cultural que se impôs, incontestada 'as demais formas. Enquanto nenhuma religião se universalizou, nenhuma língua se universalizou, nenhuma culinária ou medicina se universalizou, a matemática se universalizou, deslocando todos os demais modos de quantificar, de medir, de ordenar, de inferir e servindo de base, se impondo como o modo de pensamento lógico e racional que passou a identificar a própria espécie. Do homo sapiens se fez recentemente uma transição para o homo rationalis. Este último é identificado pela sua capacidade de utilizar a matemática, uma mesma matemática para toda a humanidade e, desde Platão, esse tem sido o filtro utilizado para selecionar lideranças.

Porém, a forma de propagação do conhecimento matemático se bifurca em duas vertentes: o conhecimento matemático de origem étnica (no sentido da Etnomatemática) e o conhecimento matemático formalizante (no sentido da Matemática escolarizada). Somente este último é valorizado de tal forma que reflete as últimas palavras do texto acima, servindo como o filtro para selecionar lideranças.

Mas há esforços no sentido de se minimizar essa filtragem $e$, hoje, se encontram tendências expressivas em educação, em particular, no ensino da Matemática no Brasil e no mundo, que rompem com a visão tradicional, compartimentada e linear do ensino e, em especial, do ensino da Matemática.

Todas as tendências supõem a participação ativa do aluno no processo de aprendizagem e sugerem uma relação professor-aluno em que ambos ora ensinam ora aprendem. Também o ensino da Matemática ganha um sentido bem mais amplo, superando a visão estritamente voltada ao conteúdo. Destacam-se aqui duas destas tendências relevantes para o ensino atual da Matemática:

- Etnomatemática: é uma tendência educacional cuja ênfase incide sobre a valorização e a busca do conhecimento cultural em seus diversos contextos. Voltase para qualquer forma de conhecimento cultural ou atividade social que possa ser utilizada no processo ensino-aprendizagem.

Segundo COSTA e BORBA (1996:91), a Etnomatemática surgiu nos anos 70 , devido à preocupação de estudiosos do Terceiro Mundo com a posição da Matemática nos sistemas educacionais, que enfatizavam os efeitos negativos que a má adaptação do ensino da Matemática às condições sócio-culturais de tais países resultaria contra o eurocentrismo matemático. Salientam ainda que:

O termo Etnomatemática, (...), foi sugerido por D'Ambrósio. Ele diz que o radical etno deve ser aceito como referente ao contexto cultural incluindo, assim, considerações como linguagem, jargâo, códigos de comportamento, mitos e símbolos. Matema seria explicar, conhecer, entender e, finalmente, tica (originária de techme) que é a mesma raiz de arte ou técnica de explicar, de conhecer, do entender os diversos contextos culturais. 
D'AMBRÓSIO (2001: 22-23) comenta a respeito da Etnomatemática afirmando que:

Há inúmeros estudos sobre a Etnomatemática do cotidiano. É uma Etnomatemática não aprendida nas escolas, mas no ambiente familiar, no ambiente dos brinquedos e do trabalho, recebida de amigos e colegas...

O autor complementa seu comentário, lembrando estudos como o de Terezinha Nunes, David Carraer e Ana Lúcia Schliemann (1988), que destacam o aprendizado de uma aritmética sofisticada desenvolvida por crianças que ajudam os pais em feiras livres, lidando com dinheiro, passando troco e oferecendo descontos sem levar prejuízo (D'AMBRÓSIO, 2001: 23).

- Construtivismo: é uma proposta pedagógica que destaca o conhecimento enquanto processo de construção. Parte do princípio de que é o próprio aluno que constrói sua compreensão do conceito, em sua interação com o ambiente, o aluno (sujeito) e o meio (objeto) constituem uma totalidade. $O$ conhecimento surge da interação entre ambos.

Segundo RANGEL (2002:58):

(...) O papel do professor no ensino construtivista é muito importante, no sentido de organizar as propostas didáticas adequadas aos diferentes conteúdos propostos, intervindo sempre, suscitando novos desafios de forma que o aluno esteja sempre aprendendo mais, estruturando seu conhecimento em níveis de pensamento cada vez mais complexos.

Em relação à realidade do aluno, RANGEL (2002:6263) diz que:

(...) no construtivismo, o conhecimento acadêmico não pode reduzir-se à transmissão dos saberes culturais e/ou científicos. Esses saberes são sempre provisórios, efềmeros. O que é uma verdade científica hoje poderá se tornar uma não-verdade amanhã. É preciso criar um espaço não de transmissão, mas de reinterpretação do saber.

Destas considerações acima, pode-se inferir que o conhecimento necessário ao pleno desenvolvimento do sujeito inserido na sociedade atual deve ser um misto do conhecimento escolar apoiado no conhecimento não escolarizado no sentido de uma reinterpretação deste no contexto da sala de aula.

Para que essa integração seja possível, é necessário que os professores, e em especial os professores de Matemática, sejam sensibilizados a desenvolver suas atividades baseadas em algumas destas tendências, isto porque o ensino da Matemática atualmente tem uma função importante que é lançar mão de todos os recursos necessários para uma aprendizagem significativa da Matemática escolarizada. Ao aluno deve ser dado o direito de aprender, não de forma repetitiva, sem saber o que e o porquê ele faz, muito menos um "aprender esvaziado nas brincadeiras e jogos", como comumente se observa nas séries iniciais.
O professor deve proporcionar ao aluno um aprender com significados do qual este (o aluno) participe raciocinando, compreendendo, reelaborando o seu conhecimento matemático na direção observada acima, isto é, reinterpretando o seu cotidiano no contexto dos conteúdos matemáticos escolarizados.

É neste sentido que LERNER e SADOVSKY (1996), afirmam que:

\begin{abstract}
Trabalhar com os números inseridos no uso que socialmente se faz deles_quer dizer, com os números representando preços, idades, datas, medidas... é fundamental, não só porque lhes outorgamos sentido, mas também porque torna possivel entender como funcionam em diferentes contextos. Trabalhar com os números fora de contexto também é significativo, porque os problemas cognitivos que se formulam são os mesmos que aparecem nas situações contextualizadas e porque a interação com os números sem qualquer relação contextual coloca em primeiro plano que se está trabalhando sobre o sistema de numeração, quer dizer, sobre um dos objetos que a escola tem a missão de ensinar e as crianças a missão de aprender.
\end{abstract}

O texto acima faz referência à missão da escola de ensinar e à missão da criança de aprender, mas para nós essa é uma missão do cidadão, qualquer que seja sua idade, sob o risco de sua exclusão social, como se observa no cotidiano da sociedade.

Prosseguindo na evolução histórica da Matemática tem-se que na fase moderna, na Alemanha (1872), Feliz Klein propõe uma maior articulação entre os distintos campos da Matemática, como também, entre as outras áreas do conhecimento. Neste sentido, SILVA diz que: “(...) surge, pela primeira vez, a idéia de Educação Matemática, desencadeando o primeiro movimento internacional para a modernização do ensino da matemática" (texto mimeografado).

No Brasil somente em 1928 é que são iniciadas as mudanças quando são feitas propostas no programa de Matemática do Colégio Pedro II e com continuidade com Malba Taham e durante o movimento escolanovista nos anos de 1920 a 1940.

Um acontecimento mundial interrompeu a evolução natural da Matemática. Tal acontecimento foi o lançamento do primeiro satélite artificial, o Sputinik, em 1957, pela União Soviética. Isso provocou não só um impacto mundial, mas também mudanças no aspecto curricular, trazendo a idéia de autonomia dos alunos.

Muita crítica sofreu a Matemática moderna, conforme diz SILVA (texto mimeografado):

(...) foi um fracasso, dada à sucessiva carga de novos símbolos e idéias, às vezes desnecessárias, que eram introduzidas abruptamente. No Brasil, somente a não preparação de professores já era razão suficiente para que o ensino da 'matemạ́tica moderna' resultasse em um verdadeiro desastre. 
Na atualidade a Educação Matemática se amplia, no sentido em que passa a ser compreendida como área de conhecimento que congrega com vários outros ramos do conhecimento: a sociologia, a pedagogia, a filosofia e a psicologia.

Em função dessa amplitude, SILVA (texto mimeografado) divide em quatro periodos o surgimento da Educação Matemática como ciência:

- $1^{\circ}$ Período: Gestação da Educação Matemática (antes de 1970) que se preocupou com o que e como ensinar.

- $2^{\circ}$ Período: Nascimento da Educação Matemática (1970), caracteriza-se pelo extremo uso do tecnicismo e pela ênfase na utilização de materiais didáticos.

- $3^{\circ}$ Período: Predomínio da Formação (década de 80 ). Aqui a preocupação é com o porquê e para quem ensinar.

- $4^{\circ}$ Período: Resolução dos Problemas (anos 90). A característica marcante desse período é relacionada com o contexto histórico no qual vive-se hoje.

Assim, os princípios norteadores da Matemática na atualidade se caracterizam em relacionar as observações do mundo real com representações (esquemas, tabelas, gráficos) dadas no ensino da Matemática escolar.

É nesta perspectiva que a Matemática é importante para a construção da cidadania, uma vez que a sociedade se utiliza cada vez mais, de conhecimentos cientificos e recursos tecnológicos, dos quais os indivíduos devem se apropriar.

Mas tal apropriação deve levar em conta o casamento entre o conhecimento não escolar e o conhecimento escolarizado, no sentido de uma transposição do conhecimento não sistematizado para um conhecimento sistematizado e formalizante, capaz de suprir as demandas de estruturas cognitivas capazes de suportar o devir do conhecimento científico e da apropriação dos recursos tecnológicos.

\section{Ensino da Matemática: uma experiência na escola São Pedro da comunidade Mocajatuba-PA}

A relação do ensino da Matemática com a realidade vivida pelos alunos da Escola São Pedro é um tema importante, porque sua discussão aponta perspectivas na direção de organizar e selecionar conteúdos voltados para uma abordagem que permita ao aluno fazer as resoluções dos problemas matemáticos partindo de situações vividas no cotidiano.

O trabalho se deu com uma turma de 30 alunos, onde a maioria trabalhava na roça. Aqui deve ser analisada a atividade desenvolvida a partir do núcleo familiar, onde a mão-de-obra infantil é bastante utilizada, fator que contribui para a grande incidência de evasão escolar, porque culturalmente se prioriza o trabalho em detrimento da educação, dada a necessidade de sobrevivência familiar.

As crianças da comunidade de Mocajatuba, por trabalharem na roça com seus pais, sentem-se bastante cansadas e isso ocasiona baixa qualidade no processo ensino-aprendizagem.
O século XXI é considerado como o século em que a máquina veio para substituir o homem, porém, na Região Amazônica se observa o distanciamento desta realidade futurista de boa parte do planeta e, às vezes, é o homem que, não longe de ser substituído pela máquina, ainda é necessário nos meios de produção nesses pequenos interiores do Brasil, em especial da Amazônia.

Observa-se que o uso amplo de máquinas nas propriedades rurais é um fenômeno relativamente recente. Hoje, o maquinário agrícola é um elemento central da agricultura, particularmente para plantação de safras. Porém, isso não ocorre em todas as regiões. Existem localidades, como é o caso da referida comunidade em que a chamada "modernização agricola" ainda não chegou, que forçam os moradores a utilizarem instrumentos rudimentares para plantar e arar a terra.

Não tendo grandes oportunidades de estudar e aprender, essas comunidades resolvem seus problemas diários em função do que conseguem reproduzir do conhecimento historicamente acumulado, o que vem a ser um campo rico de investigação na concepção da Etnomatemática. Nessa perspectiva, afirma D'Ambrósio (2001:9) que a

Etnomatemática é matemática praticada por grupos culturais, tais como comunidades urbanas e rurais, (...) que se identificam por objetivos e tradições comuns aos grupos.

Fundamentando-se na concepção teórica da Etnomatemática é que se pretende analisar a experiência em estudo.

Neste caminhar tivemos a oportunidade de participar da vida desta comunidade muitas vezes, observando vários episódios do convívio da roça. Demo-nos conta de como é importante e extraordinário o desenrolar dessas atividades que têm a ver com a Matemática na vida cotidiana.

Um desses episódios diz respeito à maneira como as pessoas se comportam no momento de medir a terra para a lavoura. Uma das unidades de medidas utilizadas é chamada de "braça" (antiga medida de comprimento equivalente a 2,2 m) e outra denominada de "tarefa" (parte de uma empreitada) dividida entre muitas pessoas. Empreitada é uma forma de serviço feito entre o patrão e o trabalhador, onde o pagamento é ajustado podendo ser dividido em duas parcelas.

Um outro elemento cotidianamente utilizado pela comunidade é o excessivo uso do cálculo mental, definido por eles como "cálculo de cabeça", por apresentar resultado rápido, sendo desnecessário o material usualmente utilizado na escola como lápis e papel.

O cálculo mental pode ser um instrumento de reflexão para o ensino da Matemática, como, por exemplo, o aluno na vida diária, estima com êxito que $R \$ 1,00$ (um real) é suficiente para se comprar 10 pãezinhos, cujo preço unitário é de $\mathrm{R} \$ 0,08$ (oito centavos), mas fracassa quando precisa multiplicar por 3 (três) em sala de aula. 
Isto nos leva a uma reflexão: Por que fora da sala de aula o aluno consegue pensar "se eu comprar 10 pãezinhos custarão $R \$ 0,80$ (oitenta centavos) e terei $R \$ 0,20$ (vinte centavos) de troco, que é suficiente para eu comprar mais dois pães"? Por que não podemos favorecer o uso dessas relações já conhecidas do aluno e incentivar o seu desenvolvimento no trato com a Matemática escolarizada?

O trabalho com cálculo mental auxilia o aluno a estruturar o seu desempenho, visando rapidez na obtenção e na precisão do resultado.

Selecionar os melhores caminhos, em qualquer atividade de cálculo mental, é sempre uma situaçãoproblema, interpretada de maneira diferente da Matemática escolarizada onde se privilegia o papel e o lápis. Pensamos que o importante seria proceder ao cálculo mental demonstrado oralmente e, se houvesse a necessidade de efetuar algum registro, que acontecesse após a descoberta do aluno.

Dos episódios observados na comunidade em questão, outro fator chamou-nos a atenção: foi sobre como se trabalha a colheita de milho e como a venda desse produto é efetuada pelo roceiro.

Um de nossos alunos trabalhava já há muito tempo na roça e não sabia quase nada da leitura e da escrita. Tal aluno dizia estar na escola para aprender um pouco mais do que já sabia, e declarou que seu pai também trabalhava na roça há muito tempo, plantando e colhendo milho, sendo este o principal produto produzido e comercializado pela familia para fazer frente às necessidades de seu núcleo familiar.

Revelou-nos o aluno como sua família fazia para controlar a produção e a coleta das espigas de milho no tempo da colheita dessa monocultura. Tal episódio nos fez ver a importância do conhecimento prévio do aluno para a introdução do conhecimento matemático escolarizado e que nós, professores, não costumamos utilizar como elemento de ligação entre esses dois tipos de conhecimento.

É neste processo de interligação dos dois conhecimentos que se pode entender o que vem a ser uma das facetas do ensino contextualizado, defendido pelos teóricos da Educação e em especial da Educação Matemática. Neste sentido, concordamos com RANGEL (2002:62) quando afirma que:

"Partir de" não significa "ficar apenas com". Restringir $o$ acesso dos estudantes de classes populares à cultura $\mathrm{e}$ a conhecimentos novos porque lhe são estranhos, porque não fazem parte do seu contexto social, pode significar restringir-lhes o acesso a outro nível social e profissional.

$\mathrm{O}$ aluno declarou que procedia da seguinte maneira: enchia um balaio (cesto) com espigas, despejando a seguir em um caminhão onde vendia seu produto na estrada.

Para cada balaio despejado no caminhão separava uma espiga em um canto, formando aos poucos um montinho. Ao final do trabalho, o número de espigas do monte correspondia ao número de balaios recolhidos.
Assim era efetuado o cálculo de quanto receberia ao final do dia e até quanto ganharia no final da colheita. $O$ interessante era que a cada grupo de cinco espigas no montinho o aluno dizia: - "Colhi mais uma mão de milho!".

Para explicar o que vinha a ser "uma mão de milho"o roceiro informou que cada cinco espigas amarradas formava uma unidade da "mão de milho" e que cinco amarrados correspondia a "uma mão de milho", correspondendo, então, a vinte e cinco espigas depositadas no balaio. Por fim, cada espiga colocada num montinho à parte representava um balaio, isto é, um grupo de espigas e na expressão "uma mão de milho", a palavra "mão" significa cinco vezes cinco, ou seja, cinco grupos de cinco espigas.

Dessa forma o aluno conseguia fazer toda a sua contabilidade da produção, coleta e fornecimento do produto de sua roça. A diferença é que não sabia formalizar esse processo na Matemática escolarizada, porém sabia muito bem calcular mentalmente, tornando fácil a contagem de grupos. Do ponto de vista da estrutura de pensamento natural, esse aluno havia assimilado muito bem o processo de contagem num sistema de base cinco, enquanto que na escola o sistema de numeração é o sistema de base dez ou decimal. Mas, do ponto de vista da matemática escolarizada, o aluno não conseguia aprender o sistema de contagem.

Isto significa dizer que o aluno possuía estrutura de pensamento matemático de forma sofisticada, mas não havia tomado consciência dessa estrutura do ponto de vista da formalização do sistema escolarizado. Dai que, mesmo não tendo conhecimento matemático escolarizado, o aluno sabia quanto lhe rendia no final do dia, da semana e do mês. Esse quadro é visto por FERREIRA (2002:10) da seguinte maneira:

"Na sala de aula, no entanto, a realidade permaneceu a mesma. Os mesmos povos que possuem riqueza conceitual e pragmática na elaboração e uso da matemática na vida cotidiana continuam fracassando nos programas escolares".

Aqui se faz uma imperiosa questão: A Matemática escolar não é a Matemática do homo rationalis?

Uma outra estrutura de pensamento matemático observado neste relato é a correspondência biunivoca que o aluno utiliza de forma prática como os primeiros pastores o faziam há milênios, isto é, uma espiga de milho separada a um canto para cada "mão de milho" colocada no balaio, tanto quanto para cada ovelha recolhida no curral, correspondia a uma pedra em um saco de couro.

$\mathrm{Na}$ verdade esse procedimento prático é uma forma de o sujeito fugir da necessidade da operação multiplicação, pois o montinho de espigas representa a quantidade de "mãos de milho" e, em última instância, a quantidade de espigas de milho. Ao aluno não interessa saber quantas espigas foram colhidas, pois este não comercializa as espigas, mas sim o conjunto de espigas que corresponde ao valor comercializado. $O$ preço pago não é por espiga, mas por "mão de milho". 
Parando-se para refletir sobre tal procedimento, mesmo que tenha sido aprendido de pai para filho, o aluno aprendeu um conhecimento matemático relevante para sua atividade e que não se diferencia do conhecimento escolar. A diferença é que este conhecimento foi incorporado à atividade cotidiana do aluno como algo não escolar e que, por não ser reconhecido como tal, não deu o "status" de conhecimento matemático.

Todo o conhecimento básico do raciocínio numérico está representado no relato do aluno tanto quanto o que faz o professor quando tenta ensinar o aluno a contar e a aprender tal conhecimento na escola.

\section{CONSIDERAÇÕES FINAIS E IMPLICAÇÕES PEDAGÓGICAS}

O objetivo neste texto foi mostrar que é possível encontrar exemplos significativos das questões teóricas colocadas pela Academia em nossas práticas do dia a dia.

De:acordo com D'AMBRÓSIO (2001:76),

Se quisermos atingir uma sociedade com equidade $\mathrm{e}$ justiça social, a contextualização é essencial para qualquer programa de educação de populações nativas e marginais, mas não menos necessária para as populações dos setores dominantes.

Ora, sendo assim, faz-se necessário o questionamento: que valor tem um conhecimento acadêmico que não pode ser contextualizado para uma parcela significativa da humanidade?

Mas, na outra ponta deste questionamento, existe um outro que o completa: como fazer para aproximar um conhecimento acadêmico do conhecimento não acadêmico no sentido de conhecimento popular?

A intenção é exatamente tentar mostrar pelo menos uma possibilidade de responder a esses questionamentos.

Primeiramente, inferir-se que falar da relação teoriaprática é falar da contextualização do conhecimento acadêmico, sem o qual o sujeito pode ficar incapacitado de acompanhá-lo.

Veja-se, pois o que D'AMBRósIO (2001:78) fala e que corrobora com nossa inferência.

$\mathrm{Na}$ aritmética, o atributo, isto é, a qualidade do número na quantificação, é essencial. Duas laranjas e dois cavalos são "dois" distintos. Chegar aos dois "abstratos", sem qualificativo, assim como chegar à geometria sem cores, talvez seja o ponto crucial na passagem de uma matemática do concreto para uma matemática teórica.

Percebe-se nas palavras deste autor que, para se atingir o sujeito com uma Matemática do abstrato, é necessário mergulhar na Matemática do concreto do sujeito e, portanto, faz sentido a inferência mencionada.

Quando o aluno pratica a concepção de número na colheita da "mão de milho", (portanto, um conhecimento popular) exercitando de forma sofisticada o sistema de numeração na base cinco e não compreende o mesmo sistema de numeração na base dez (conhecimento acadêmico praticado na escola), revela que se precisa ter "o cuidado com essa passagem e trabalhar adequadamente este momento" (idem: 78).

\section{Esse cuidado talvez sintetize}

\begin{abstract}
...O objetivo mais importante da matemática elementar. Os demais são técnicas que pouco a pouco, conforme o jovem vai tendo outras experiências, vão se tornando interessantes e necessárias. $O$ cuidado com a passagem do concreto ao abstrato é uma das características metodológicas da etnomatemática. (D'AMBRósIO, 2001:78).
\end{abstract}

$E$ isto se pode concluir que para desenvolver experiências dessa natureza com alunos, o professor tem que abrir espaços em suas aulas para que eles possam emitir e discutir suas opiniões e interpretações, explorar o conhecimento prévio e depois fazê-los registrar e discutir coletivamente suas idéias em classe.

Do ponto de vista do construtivismo, é precisamente este o comportamento a ser cultivado, isto é, o professor deve estar atento a todas as manifestações dos alunos que precisam ser interpretadas a seu favor.

Ao contrário de se considerar que um dado aluno não tem capacidade cognitiva para aprender um dado conteúdo escolar, é função do professor detectar as estruturas cognitivas subjacentes ao pensamento do aluno e procurar caminhos de provocar a tomada de consciência dessas estruturas cegnitivas naturais no contexto do conhecimento matemático escolarizado.

No caso do aluno citado, esta é uma possibilidade inconteste. Como já se relatou, o mesmo de fato já possui a estrutura de pensamento que corresponde ao raciocinio numérico. $O$ problema é que lhe faltou tomar consciência que seu modo de raciocinar com a "mão de milho" é exatamente o mesmo do raciocínio numérico na base decimal.

Bastaria, portanto, aos professores, explorarem essa forma cultural de lidar com a contagem passada de pai para filho e provocarem a tomada de consciência rumo à Matemática da sala de aula.

Na prática diária, sabe-se que os alunos gostam de ser desafiados a produzir, a comunicar e a negociar seus significados e saberes sobre o que estão aprendendo, participando das coisas e produzindo, ao invés de ouvirem as explicações prévias e realizarem exercícios descontextualizados.

Por esta razão, o professor deve estar atento aos episódios que surgem na sala de aula, haja vista que "nunca se sabe o que pode surgir das mentes que se colocam a pensar" (DORA, 2001:32). O professor, sempre que possível deve colher informações e obter registros escritos dos alunos, de preferência através de trabalhos individuais propostos em sala, procurando obter a expressão real de seus pensamentos, os seus pontos de vista, seus argumentos, justificativas, representações, interpretações e, sobretudo, os sentidos que atribuem às idéias e representações matemáticas. 
Conforme diz RANGEL (2002:56):

Quando é possivel ao professor utilizar-se de experiências e de material concreto para a descoberta de novos conceitos, isso deve ser feito. Mas quando se trata de conhecimentos abstratos, de idéias, é preciso levar em conta os conhecimentos prévios dos alunos para não lhes exigir um nível de raciocinio para o qual não possuem estruturas cognitivas já desenvolvidas, porque, neste caso, sem estarem mobilizados para o assunto, curiosos, interessados, não haverá atividade cognitiva. Da mesma forma, um assunto que já dominem ou conheçam, nada lhes provocará em termos de desafios cognitivos (não haverá atividade mental).

Desse exercício coletivo dos significados dos alunos durante o processo ensino-aprendizagem, tanto 0 professor como os alunos poderão observar o quanto foi importante discutir, falar e opinar sobre as respostas dos colegas, suas dúvidas, seus erros conceituais. Isso provavelmente levaria o aluno a participar ativamente das aulas, onde poderia perceber e corrigir seus próprios erros, encontrando várias soluções para o mesmo problema, desmistificando a Matemática como única e verdadeira ciência exata.

Corrobora com estas observações, LINS \& GIMENES (1997:79) quando citam o texto do Currículo Espanhol de 1993:

Deve-se favorecer a utilizaçâo pelos estudantes de suas próprias estratégias na atividade matemática, não só para conseguir uma aprendizagem mais funcional e desenvolver seu nível de auto-estima e auto-eficácia, mas também como expressão da criatividade e de formas de pensamento originais.

Dito isto, só nos resta sermos mais reflexivos na prática diária, de maneira a perceber que as diversas teorias sobre os problemas enfrentadas nas escolas são passíveis de serem observadas nó dia-a-dia, bem como o inverso. Encontra-se um problema aparentemente insolúvel, temse que ter a sensibilidade de não o rotular como um problema exclusivamente de um dado aluno e buscar a compreensão nos compêndios teóricos ou junto aos que se dedicam a estudá-los e, com certeza absoluta, conseguiremos uma explicação razoável.

Se assim proceder, ter-se-á encontrado uma forma capaz de minimizar as angústias profissionais e, finalmente, provocar uma auto-estima, o que virá a refletir numa educação qualitativamente diferente da atual.

\section{REFERÊNCIAS}

CARRAHER, T; CARRAHER, D; e SCHLIEMAN, A. $A$ vida dez, na escola zero. São Paulo: Cortês. 1988.

COSTA, Wanderleya N. Gonçalves; BORBA, Marcelo de Carvalho. O porquê da Etnomatemática na Educação Indígena. Zetetike, v. 4, n. 6, p. 75-85, 1996.
D'AMBRÓSIO, Ubiratan. Etnomatemática: arte ou técnica de explicar e conhecer. São Paulo: Ática, 1993. $88 \mathrm{p}$.

D'AMBRÓSIO, Ubiratan. Etnomatemática: elo entre as tradições e a modernidade. Belo Horizonte: Autêntica, 2001. Coleção Tendências em Educação Matemática. $112 \mathrm{p}$.

FERREIRA, M.K.L. (Org.). Idéias matemáticas de povos culturalmente distintos. São Paulo: Global, 2002. Série Antropologia e Educação. 336 p.

LERNER, Delia e SADOVSKY, Patrícia. O sistema de numeração: um problema didático In: PARRA, Cecília e SAIZ, Irmã (Org). In: Didática da matemática: reflexões psicopedagógicas. Porto Alegre: Art med, 1996. 258p.

LINS, R.C. \& GIMENES, J. Perspectivas em aritmética e álgebra para o século XXI. Campinas: Papirus, 1997. Coleção Perspectivas em Educação Matemática. 176 p.

MEGID, M.A.B.A. Construindo matemática na sala de aula: uma experiência com números relativos. In: FIORENTINI, D. \& MIORIM, M.A. (Org.). Por trás-da porta que matemática acontece? Campinas: UNICAMPCEMPEM-Faculdadeđde Educação, 2001. 231 p.

RANGEL, A.P. Construtivismo: apontando falsas verdades. Porto Alegre: Mediação, 2002. 80p.

SILVA, N.O. Evolução histórica do ensino de matemática. (Texto mimeografado). 